\title{
Indicators of the combine equipped with GPS receiver in sunflower harvesting
}

\author{
Otabek Ochildiev ${ }^{1, *}$, Golibjon Fozilov ${ }^{1}$, Shodi Achildiev ${ }^{2}$, Maxmud Karimov ${ }^{3}$, Nurali \\ Ashurov $^{4}$ \\ ${ }^{1}$ SRIMA, 110800 Tashkent region, Yangiyul district, Samarkand 41, Uzbekistan \\ ${ }^{2}$ TerSU, Transport Systems and Facilities Department, 190111 Termez, Barkamol avlod 43 \\ Uzbekistan \\ ${ }^{3}$ Termez branch TSTU, Electrotechnical Department, 190111 Termez, Barkamol avlod 26 \\ Uzbekistan \\ ${ }^{4}$ TIIAME, Agricultural Machines Department, 100000 Tashkent, Kari Niyaziy 39 Uzbekistan
}

\begin{abstract}
In sunflower harvesting for decreasing the grain loss and increasing using efficiency of the combines GIS technologies, namely combines equipped with GPS devices and control sensors provides good results. This is explained that by the fact that with a length of $400-500 \mathrm{~mm}$, the cut baskets did not partially fall on the divider-guide, and with a length of 700-800 mm, seed losses increased due to uncut baskets, since with an increase in length the divider-guide bent some stems forward and did not cut them. Analyzing the studies of working process of the adapted grain harvester combine Dominator-130 that equipped with GPS receiver and grain level indicator sensor in sunflower harvesting defined optimal parameters its header, as the following values: the length of the dividerguide $\left(l_{T}\right)-0.6 \mathrm{~m}$, the gap between the divider-guides $\left(S_{T}\right)-0.1 \mathrm{~m}$, the installation angle of the divider-guide relative to the bottom of the header $\left(\beta_{T}\right)-5$ degrees. With these parameters, the combine that has adapted header for harvesting sunflower meets the agro technical requirements for harvesting sunflower.
\end{abstract}

Keywords: sunflower harvesting, combine, GIS, GPS receiver, grain sensor, header, adaption, guide-divider.

\section{Introduction}

In modern agriculture, for harvesting sunflower, mainly combine harvesters are being used that equipped with a special header or adapted grain header for harvesting sunflower. In Uzbekistan, the sunflower is grown as a second crop after cereals in relatively small areas of farmers. Therefore, it is economically viable to use a combine harvester by adapting the combine header for harvesting sunflower under these conditions.

One of the important and crucial indicators when harvesting sunflower is harvesting in a short time and with minimal losses. For this, when harvesting sunflower, it is important to

\footnotetext{
* Corresponding author: otabek uzmei@mail.ru
} 
implement GIS technologies. For application on GIS technologies, it is necessary to use widely combines equipped with GPS devices and control sensors.

With using GIS technologies the working efficiency of the harvester combines is defined. Y.Cao researched on application of the Internet of things technology in financial leasing of intelligent manufacturing enterprises. In his research, he analyzed of financial leasing risk control with agricultural combine harvester has front end-speed sensor $\mathrm{A}$ is arranged at the drive shaft of the combine harvester, fuel consumption sensor B is arranged in the fuel tank, body positioner $\mathrm{C}$, weight sensor $\mathrm{D}$, distance sensor $\mathrm{E}$ are arranged, and power-off control element $\mathrm{F}$ is arranged at the ignition device. The transfered node, the company's personalized data encryption algorithm is added to ensure remote and secure transmission of information data [1].

Developed dynamic performance evaluation method of agricultural machines that equipped with DGPS devices [2]

Feasibility of low-cost GPS receivers for ground speed measurement was developed for increasing the rate of using an automatic agricultural vehicle based on low cost GPS receiver [3].

As the aim more realizing GIS technologies during the harvesting works an autopilot was developed for a combine harvester. [4].

Tractor-based Real-time Kinematic-Global Positioning System (RTK-GPS) was created for guidance system for geospatial mapping and intra-row weed knife control system [5, 6].

K.Hayashi developed a geographic information system (GIS) for collecting farming information. They decided the time from harvesting to tank discharge and proposed a method to solve the time lag of combine harvester by setting tailing return. Solving the issue of tailing return is required in order to do highly accurate yield mapping using headfeeding combine harvester $[7,8]$.

Besides of above mentioned the scientific fundamentals of sunflower harvesting are occupied by many researchers, in particular, D.Shafarostov and S.S. Makarov developed and justified the parameters of a four-row sunflower harvesting system [9].

E.I.Sitchenko developed a self-propelled machine for harvesting selective sunflower [10]. S.Sudajan, V.M.Salokhe and K.Triratanasirichai have developed a thresher for sunflower [11]. T.Csanadi and B. Hamphoff have advanced a special header for harvesting sunflower for combine harvesters CLAAS [12].

I.S.Dalmis et al developed a sunflower harvester that has a chopper under the header for chopping stems during harvesting [13,14]. A.H.Mirzabe and G.R. Chehini created a thresher for sunflower that separates grains from baskets with an air stream [15]. X.Li et al developed the ADRC-DMC controller, which for stable it controls the rotation speed of the threshing drum when harvesting sunflower [16].

In above works researches have not been carried out about adaptation and defining indicators of the grain harvester combine equipped with gps receiver and grain level sensor in sunflower harvesting. Besides this full-scale researches in this direction have not been conducted in Uzbekistan.

\section{Materials and methods}

The justification of technical means for harvesting sunflower based on local conditions is relevant. In this regard, studies were conducted and an adapter was developed to adapt the grain header for harvesting sunflower [17, 18] (Fig.1). 


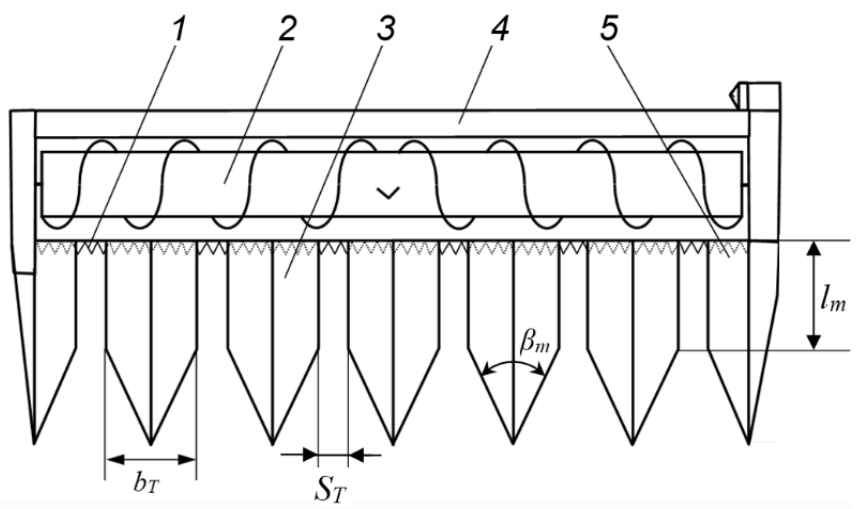

1-segment-finger cutting apparatus; 2-auger; 3-directional dividers; 4-back side of the header; 5side guide divider.

Fig. 1. Adapted grain header for harvesting sunflower.

The adapted header consists of a cutting unit, auger of header, reel and divider-guides that are mounted on top of a segmented-finger cutting unit.

In the process of harvesting sunflower for taking data about work efficiencies of combine Dominator-130 at real time regime combine was used with GPS receiver Teltonika FMB920 and grain level sensor Escort DB-2 (Fig. 2).

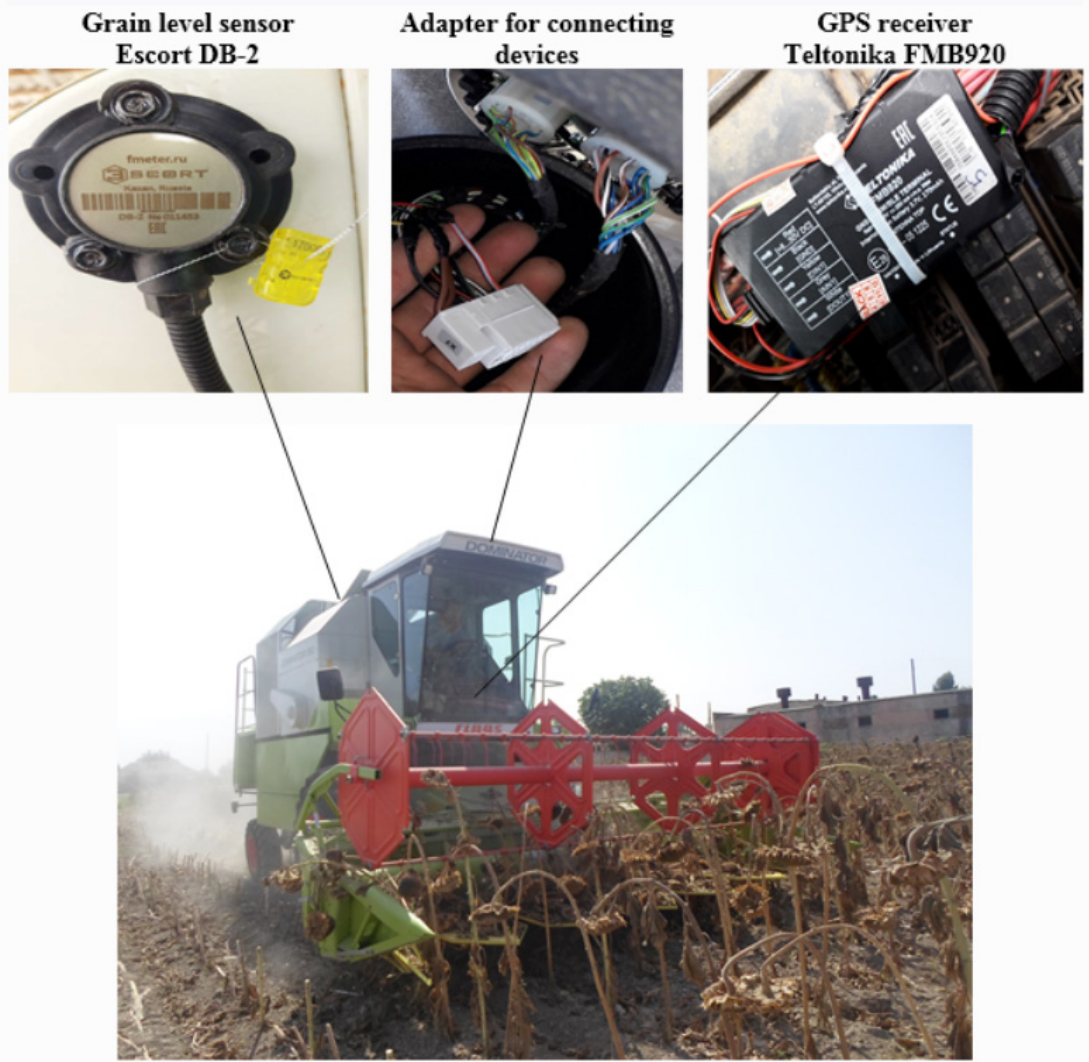

Fig. 2. Outlook of the adapted combine harvester equipped with GPS receiver, grain sensor. 
Therefore, in the process of harvesting sunflower seeds, the cut baskets, which are guiding apparatus, should fall on the divider-guide (Fig.1). For this, it is important to determine correctly the length and width of the divider guide. If a divider-guide is long, this can affect to the maneuverability of the combine. If the divider-guide is short, the cut baskets fall forward in the cutting device can fall to the ground (especially with curved stems in the direction of the combine) in front of the divider. In addition, if the gap between the dividers is too wide, then baskets with a diameter less than the gap may fail, and if the width is less than the stems that deviate strongly from the sowing line may not fall and the gap will bend under the header after $\mathrm{W}_{\mathrm{ii}}$ in increased grain loss. Therefore, it is very important to determine the optimal parameters of the divider-guide.

\section{Results and discussion}

At first we conducted experimental studies to find the optimal value of the length of the guide-divider. At which the loss of seeds was determined depending on the length of the guide-divider (Fig.3).

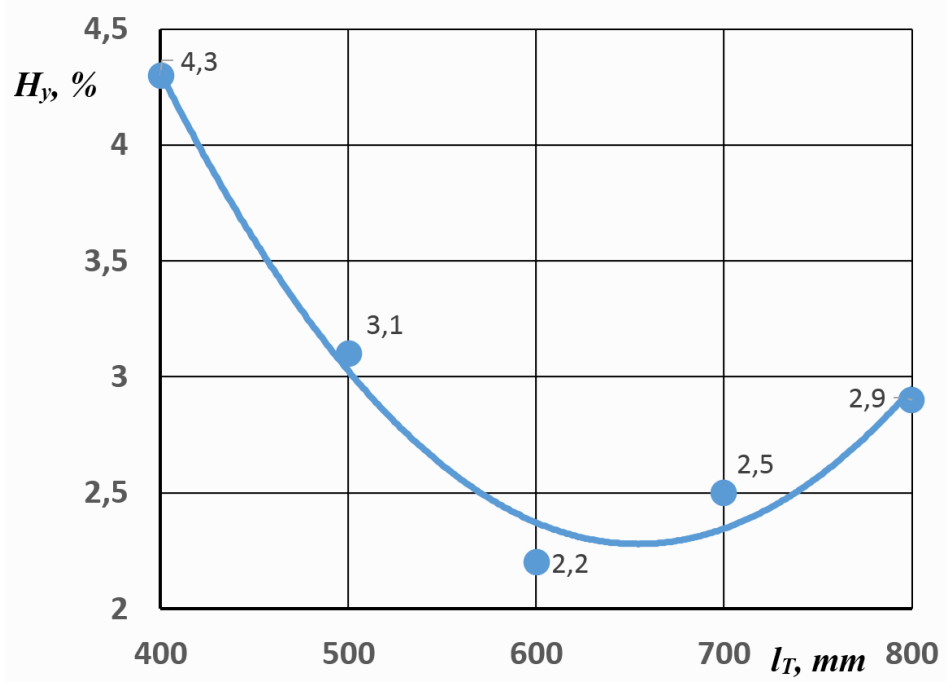

Fig. 3. The influence of the length of the dividers-guides $\left(l_{T}\right)$ on the loss of sunflower seeds $\left(H_{y}\right)$ behind the header.

It can be seen from the graph (Fig. 3) that with the length of the divider guides from 400 $\mathrm{mm}$ to $600 \mathrm{~mm}$, the seed loss changed in the direction of decreasing from 4.3 percent to 2.2 percent. Further, with an increase in the length of the guide divider $(700 \mathrm{~mm})$, the seed loss increased from 2.5 percent to 2.9 percent $(800 \mathrm{~mm})$. This is explained that by the fact that with a length of $400-500 \mathrm{~mm}$, the cut baskets did not partially fall on the divider-guide, and with a length of 700-800 mm, seed losses increased due to uncut baskets, since with an increase in length the divider-guide bent some stems forward and did not cut them.

The width of the divider guide should be less than the minimum distance between the extreme points of the sunflower stalks in the row spacing and greater than or equal to the distance between the fingers of the cutting apparatus. Given that the distance between the fingers is $7.6 \mathrm{~cm}$, with a row spacing of $70 \mathrm{~cm}$, the width of the divider should be greater or equal to $62.4 \mathrm{~cm}$ and less than the deviation of the plants from the centerline of the row. Therefore, to determine the optimal width of the divider guide, experimental studies were 
performed, namely the influence of the gap between the dividers (divider width) on the loss of sunflower seeds behind the header was determined (Fig.4).

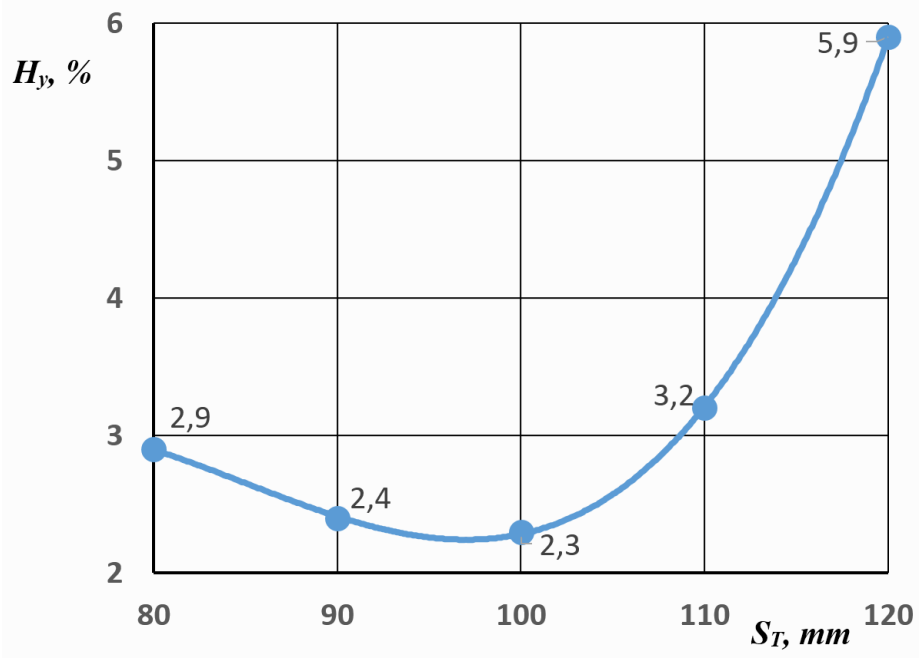

Fig. 4. The influence of the gap between the dividers $\left(S_{T}\right)$ on the loss of sunflower seeds $\left(H_{y}\right)$ behind the header.

As can be seen from the graph (Fig. 4), with a gap of $80 \mathrm{~mm}$, the loss of seeds was 2.9 percent, with a gap of $100 \mathrm{~mm}$, the loss was 2.3 percent, then with an increase in the gap $(120 \mathrm{~mm})$ the loss of seeds increased from 3.2 percent to 5,9 percent $(140 \mathrm{~mm})$.

This is because with a gap of $80 \mathrm{~mm}$, some stems that deviate strongly from the sowing line bend under the header, and with a gap of $120-140 \mathrm{~mm}$, cut baskets with a small diameter fall into the gap.

Next, we conducted studies to determine work efficiencies of combine Dominator-130 with the guide-divider at real time regime using GPS receiver Teltonika FMB920 and grain level sensor Escort DB-2. The results this experiment shown in the table 1.

Table 1. Influence to combine work quality indicators of work velocity changing of the combine Dominator-130

\begin{tabular}{|c|c|c|c|c|c|}
\hline \multirow{2}{*}{\multicolumn{2}{|c|}{ Work quality indicators }} & \multicolumn{4}{|c|}{ Velocity of the combine harvester, $\mathrm{m} / \mathrm{s}$} \\
\hline & & 0.6 & 0.9 & 1.2 & 1.5 \\
\hline \multicolumn{2}{|c|}{ Work capacity, ha/hour } & 0.83 & 1.13 & 1.47 & 1.82 \\
\hline \multirow[t]{2}{*}{ Losses, $\%$} & In combine header & 0.36 & 0.40 & 0.47 & 0.84 \\
\hline & In combine thresher & 0.50 & 0.68 & 0.92 & 1.64 \\
\hline
\end{tabular}

According to data of GPS receiver, when work velocity of the combine was $0.6 \mathrm{~m} / \mathrm{s}$, its work capacity in main time became 0.83 ha/hour. As the velocity of the combine increased to $0.9,1.2$ and $1.5 \mathrm{~m} / \mathrm{s}$, work capacity of the combine harvester constituted $1.13,1.47$ and $1.82 \mathrm{ha} /$ hour respectively. Seed losses increased too while velocity of the combine increased. In this situation, when velocity of the combine rose, seed losses was significantly in the header of the combine and made up $0.36,0.40,0,47$ and 0.84 per cent. In thresher of the combine harvester seed losses that are free form were equal to $0.50,0.86,0,92$ and 1.64 per cent accordingly to velocities. It has been known that, work velocity of the combine harvester should not be no more than $1.2 \mathrm{~m} / \mathrm{s}$, this has been founded as optimal. 


\section{Conclusion}

Analyzing the studies of working process of the grain harvester combine Dominator130 that equipped with GPS receiver and grain level indicator sensor in sunflower harvesting we have taken optimal parameters, as the following values: the length of the divider-guide $\left(l_{T}\right)-0.6 \mathrm{~m}$, the gap between the divider-guides $\left(S_{T}\right)-0.1 \mathrm{~m}$. With these parameters, the combine that has GPS receiver, grain level indicator sensor and adapted header for harvesting sunflower meets the agro technical requirements for harvesting sunflower. 2015.

The study was funded by the Uzbekistan Applied Research Foundation, grant No KHA-3-007-

\section{References}

1. Y. Cao, The International Journal of Advanced Manufacturing Technology (2019)

2. S. Han, Q. Zhang, H. Noh, B. Sin, Transactions of the ASAE, 47(1), (2004)

3. M. Keskin, S. M. Say, Computer and Electronics in Agriculture, 54, (2017)

4. T. Coen, A.Vanrenterghem, W. Saeys, J. De Baerdemaeker, Computers and Electronics in Agriculture, 63, (2008)

5. M. Perez-Ruiz, D. C. Slaughter, C. Gliever, S. K. Upadhyaya, Biosystems Engineering, 111, (2012)

6. M. Perez-Ruiz, D. C. Slaughter, C. Gliever, S. K. Upadhyaya, Computers and Electronics in Agriculture, 80, (2012)

7. K. Hayashi, Journal of Japanese Society of Agricultural Machinery, 69(5), (2007)

8. K. Hayashi, Journal of Japanese Society of Agriculture and Biological Engineering, 6, (2014)

9. D. V. Shafarostov, S. S. Makarov, ACTA Technological Agriculture, 22(2), (2019)

10. E. I. Sitchenko, Research Institute of Oil Crops, 124, (2001) (in Russian)

11. S. Sudajan, V. M. Salokhe, K. Triratanasirichai, 83 (4), (2015)

12. T. Csanadi, B. Hamphoff, VDI Berichte, (2007)

13. I. S. Dalmis, B. Kayisoglu, Y. Bayhan, P. Ulger, F. Toruk, F. Durgut, Bulgarian Journal of Agricultural Science, 19(5), (2013)

14. I. S. Dalmiş, B. Kayişoğlu, Y. Bayhan, F. Toruk, F. T. Durgut, Tarim Bilimleri Dergisi, 19 (1), (2013)

15. A. H. Mirzabe, G. R. Chegini, Agricultural Engineering International: CIGR Journal, 17(3), (2015)

16. X. Li, X. Zhang, X. Zhu, Journal of Agricultural Mechanization Research, 7, (2019)

17. K. Astanakulov, O. Ochildiyev, European science review, 1, (2018)

18. K. D. Astanakulov, O. Sh. Ochildiyev, In Proceedings of the III Tashkent international innovation forum, (2017) 